\title{
Leer versos con los ojos de la historia. Literatura y Nacion en Ricardo Rojas y Jorge Luis Borges
}

Patricia FUNES ${ }^{1}$

RESUMEN: El artículo analiza las representaciones de la "argentinidad" a partir de la construcción del canon literario en la década de 1920. En esta oportunidad se ha elegido confrontar la ensayística de Ricardo Rojas y Jorge Luis Borges. A nuestro juicio las fundamentaciones sobre la existencia o la voluntaria construcción de una "historia de la literatura nacional" descubre en sus mecanismos de selección, hermenéutica y fundamentación, el conflicto por definir los significados de la identidad nacional. Constructivistas o identitarias, particularistas o universalistas, tradicionalistas o vanguardistas, la cuestión trasciende el campo literario y es fundacional de imágenes, símbolos y estereotipos que desde el campo intelectual se vuelcan a las representaciones de la sociedad y la política.

PALA BRAS ClAVES: nacionalismo, vanguardia, historias de la literatura.

\section{LAS HISTORIAS DE LA LITERATURA NACIONAL}

La construcción de una tradición impone forjar un abolengo, un linaje que revele espesuras, honduras e inmemorialidades, (que el acto "original" de la construcción vuelve precisamente recordable e historiable) para conjurar las inestabilidades e incertidumbres del futuro. En este sentido, tradición y modernidad no se oponen, se complementan. Es la modernidad la que necesita de tradiciones. Aunque secularizadas y laicas, también elabora sus panteones y rituales. La historia, los museos, los sitios arqueológicos, las exposiciones nacionales, fueron los soportes que expresaron las búsquedas e invenciones de lo nacional. En este sentido, consideramos que las polémicas sobre el idioma 
nacional y también la construcción del canon literario son representaciones muy elocuentes de las formas y contenidos que pretendía dotarse a la nación. A nuestro juicio las fundamentaciones sobre la existencia o la voluntaria construcción de una "historia de la literatura nacional" descubre en sus mecanismos de selección, hermenéutica y fundamentación, el conflicto por definir los significados de la identidad nacional. Constructivistas o identitarias, particularistas o universalistas, tradicionalistas o vanguardistas, la cuestión excede el campo literario y es bien demostrativa de vocaciones más pretensiosas. El conflicto por definir la argentinidad en los años veinte, es fundacional de planteos que desde el campo intelectual se vuelcan a las representaciones de la sociedad y la política.

En la década de 1920 en varios países de la región y al calor de la pregunta sobre la identidad nacional surgen esas narraciones metaliterarias que son las historias de la literatura. Si las naciones, al decir de Hobsbawm, son obras muy complejas de "ingeniería social", consideramos que parte de esa ingeniería se objetiva en el terreno de las subjetividades (valga el oxímoron) y a través de materiales simbólicos.

Las historias de la literatura son territorios generosos para recrear las coordenadas de la discusión acerca de la nación. A nuestro juicio, en los años veinte el concepto "nación" deja de ser un adjetivo del estado y se desliza hacia consideraciones identitarias, idiosincráticas y muchas veces, esencialistas.

Es interesante advertir el doble movimiento que se experimenta en el imperio genérico de las "letras". Por un lado: el compendio y el relevamiento y, por otro, la hermenéutica en términos de "lo nacional". Un movimiento que no carece de tensiones, que se resuelven muchas veces en la cómoda y generosa forma del "ensayo. Aun cuando se tratara de "institucionalizar" las letras argentinas a través de la creación de la cátedra de Literatura Argentina en la Facultad de Filosofía y Letras de la Universidad de Buenos Aires, la Historia de la Literatura Argentina, de Ricardo Rojas, lleva como subtítulo Ensayo Filosófico sobre la evolución de la cultura en el Plata. ${ }^{2}$ Esto no sólo ocurría en Argentina. Contemporáneamente en Uruguay Alberto, Zum Felde se abocaba a la misma tarea: 
Este estudio implica [...] una completa revisión de los valores literarios circulantes en el país. No habiéndose ejercido anteriormente esta crítica científica respecto de nuestra literatura, lamentables errores de concepto confundían el juicio dominante; por lo cual [...] hemos tenido que realizar un trabajo de discernimiento y ordenación fundamentales. ${ }^{3}$

La línea divisoria entre la "crítica literaria”, la "sociología”, la historia, la literatura y la política se vuelve borrosa aunque se asista a un embrionario proceso de diferenciación. Se rompe, en primer lugar, con una consideración exclusivamente "estética" del hecho literario y con la concepción de las belles-lettres que la sustentaba. Por ejemplo, el crítico peruano Luis Alberto Sánchez proponía la creación de una disciplina nueva, emparentada con la sociología "una ciencia o un método que debe optar un nombre adecuado e intransferible: por ejemplo, el de Socioliteratura." ${ }^{4}$ La metodología de la selección y los marcos conceptuales para recortar el objeto literario llevan a la necesidad de explicitar esas tradiciones señalando las autoridades de las que se parte:

...la literatura, como quiera que se la mire, bien sea desde un punto de vista artístico, bien desde la trinchera mesológica de Taine, bien desde el mirador de Brunetière, bien desde la dialéctica marxista, la literatura es el resultado, elaboración, producto de un largo proceso en el que actúan conjuntamente todas las fuerzas de la naturaleza y del hombre, flor de la historia de un pueblo, espuma de su dolor y su alegría. ${ }^{5}$

Se cuela en casi todas las exégesis un historicismo romántico tensionado (y a veces "traicionado") por heteróclitas opciones metodológicas. Un elemento que queremos destacar es la conciencia de lo fundacional del acto de la compilación y la selección. Allí radica una actitud, a nuestro juicio, dilemática. Los incipientes historiógrafos literarios admiten la "juventud" y "brevedad" de la historia de los países latinoamericanos, lo que influía necesariamente en el corpus literario a analizar, pero por otra parte, necesitaban demostrar que existía cierta "masa crítica" para ser recuperada. Esa tensión entre la exhaustividad y la relevancia explica el eclecticismo de los caminos teóricos, ya que se trataba 
de "compendiar", de demostrar la existencia de producción literaria suficiente para ser analizada. Esto se contrapone con la intención "crítica", que requiere de un proceso de "selección", según la prescriptiva del campo "científico" de las historias de las literaturas europeas, asunto que marcaba la diferencia entre el mero "anticuario” y el crítico.

Esa dualidad se advierte en el prólogo de Rojas a la Historia quien expresa que tomó la cátedra de literatura nacional "sin tradición y sin bibliografía”. El problema no sólo era el páramo precedente sino también las emblemáticas "autoridades" (el ubicuo e insoslayable Bartolomé Mitre, por ejemplo) que habían negado de plano -no sin sólidas razones- la existencia de una literatura nacional:

Para llegar a estos nuevos conceptos y fundarlos en sólidos materiales, debí, durante varios años, remover varios archivos privados y públicos, consultar epistolarios y memorias, revisar bibliotecas enteras, rastrear el inexplorado caudal paleográfico, rever lo impreso [...]. Ví que teníamos materiales para una obra de esta índole, después de cuatro siglos de vida mental en nuestro territorio. ${ }^{6}$

El incipiente proceso de codificación disciplinaria fue marcando el perímetro de unos saberes hasta entonces sin abolengo. Acto explícitamente fundante que definió retrospectivamente los alcances de las humanidades previas bajo el imperio del "autodidactismo", el diletantismo, o la improvisación. Esa paulatina autonomización de las disciplinas supuso relevar, elegir métodos y construir objetos, diseñar estrategias de difusión.

El inventario no era suficiente para saldar el objetivo de Rojas: "historiar las emociones, los sentimientos, las pasiones, las ideas, las sensaciones y los ideales argentinos, tomando como signo de esos estados del alma a nuestra literatura". Eso implicaba no solamente el recorte de un objeto sino criterios de selección que no podían ser espontáneos, no sólo por la pretensión "científica" que los animaba, sino porque ese inmanente espíritu nacional que Rojas buscaba no se "revelaba" con la mera enumeración: "era menester, con doctrina filosófica, organizarlos en un sistema de belleza, de verdad y de vida, o sea, 
descubrir la ley oculta del proceso histórico y la expresión de nuestra propia estética."

Rojas descarta la "falta de todo sistema, que descoyunta los estudios de Menéndez y Pidal, y el exceso de sistema, que osifica los estu-

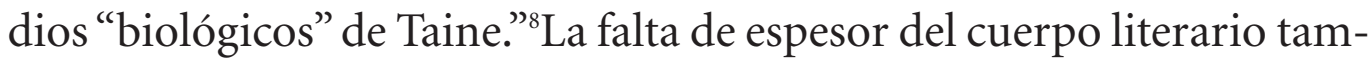
poco habilitaba muchas referencias ya bastante envejecidas y superadas pero que Rojas necesita nombrar: los métodos biográficos de Faguet en Francia, Carducci en Italia, Macaulay en Inglaterra, Menéndez y Pelayo en España. Rojas opta, entonces, por una síntesis entre el modelo de Taine (raza, medio, momento) suavizado y flexibilizado neorrománticamente con el "genius" que se despliega de manera historicista (y teleológica) hacia la representación de lo nacional. Por eso hace explícito un eclecticismo que oscila entre la "ley biológica" y la "intuición":

...yo no he concebido un a priori un sistema de clasificación, para deformar los hechos forzándolos a entrar en ese molde teórico; he acumulado los hechos literarios y descubierto en ellos, por intuición, la ley biológica que los rige en nuestro medio, como norma de la creación estética. La realidad de esa ley, califica nuestra bibliografía como un todo orgánico, demostrando a su vez la existencia de un alma nacional, sujeto pensante de la literatura argentina, y la existencia de una literatura nacional como expresión del alma argentina. ${ }^{9}$

Otro territorio contribuía, en los años veinte, a delimitar el objeto "literatura nacional": la política. En este sentido, es muy interesante la polémica que mantiene Víctor Andrés Belaúnde hacia finales de la década, respecto de las consideraciones de Mariátegui sobre la literatura en Perú. En el último de los Siete Ensayos ("Proceso de la literatura”) el director de Amauta expone franca y provocativamente la relación entre los estudios de la literatura y el nacionalismo. Citando a clásicas referencias (Schlegel, De Sanctis, Brunetière, Croce), afirma de manera genuinamente "moderna":

El florecimiento de las literaturas nacionales coincide, en la historia de Occidente, con la afirmación política de la idea nacional. El "nacionalis- 
mo" en la historiografía literaria, por tanto es un fenómeno de la más pura raigambre política, extraño a la concepción estética del arte. ${ }^{10}$

De allí que prevenga al lector sobre su punto de partida: "Declaro sin escrúpulos que traigo a mi exégesis literaria todas mis pasiones e ideas políticas, aunque, dado el descrédito y degeneración de estos vocablos en el lenguaje corriente debo agregar que la política en mí es filosofía y religión." ${ }^{11}$ La petición de principios mariateguiana le resulta inadmisible a Víctor Andrés Belaúnde ${ }^{12}$ pero la misma controversia lo obliga a desnudar sus propios presupuestos filosóficos e ideológicos:

$\mathrm{Al}$ error esencial en el marxismo de reducir el fenómeno literario al fenómeno económico, agrega Mariátegui el de contemplar y apreciar la producción literaria con criterio político. Nosotros [...] sentimos como una sensación de libertad y de ascensión, frente al criterio rígido y descendente, de la filosofía materialista. Dentro de la mentalidad católica, que es la única en que se estructura la independencia y la jerarquía de los diversos aspectos de la realidad, han vivido los artistas más libres: Dante, Cervantes, Claudel... ${ }^{13}$

El criterio político se cuela, más explícitamente, en las formas de organización de la historia literaria. El recurso más frecuente es el del cruce entre criterios estéticos, de escuelas y el histórico- político. Ricardo Rojas periodiza decididamente con la historia política del país ${ }^{14}$, cruzándola con tres momentos o sensibilidades culturales (clasicismo, siglo XVII, romanticismo, siglo XIX y modernismo, "en la época actual"). Sin embargo, el eje histórico- político es el organizador de la obra. Incluso uno de los cuatro tomos de su Historia se llama decididamente "los proscriptos". Aunque la cronología sea tan cara a los historiadores, no duda en cambiar "heréticamente" el orden de aparición de los volúmenes. No comienza con Los coloniales sino con Los gauchescos. Las razones, son suficientemente fuertes para el autor, y obviamente tienen un carácter extraliterario. Hasta la Historia, "la existencia misma de una literatura argentina -no, por supuesto, de libros escritos en la Argentina o por argentinos- debía ser probada. En verdad, se tra- 
taba de "afirmar y probar" que una identidad nacional y una tradición literaria se abrían paso a través de los textos y para ello no era suficiente ni la mera existencia de estos, ni su ordenación cronológica. Por eso, Rojas no comienza su Historia de la literatura argentina con "los coloniales, sino con los gauchescos [...] que son la roca sobre la que se funda el desarrollo de ese documento de la conciencia colectiva: la literatura argentina." ${ }^{15}$

A veces los criterios estéticos se ven subordinados a esa necesidad de "probar" la existencia de literatura argentina, incorporaciones más animadas por la vocación inclusiva y enumerativa que crítica, actitud señalada por sus contemporáneos:

Erróneo nos puede parecer el criterio nacionalista de tan sesudos críticos como Rojas, el argentino, al querer dar valía ante el juicio contemporáneo a poetastros tan enfáticos como Olegario Andrade [...]. Toda la poesía romántica argentina debe ser borrada del libro de la posteridad. ${ }^{16}$

Otra decisión en la construcción del objeto era la delimitación espacial y temporal del adjetivo nacional. Para casi todos los críticos, con más o menos énfasis, el registro y análisis de lo "nacional" comienza en la colonia (por eso Rojas habla de "cuatro siglos de historia"). Sin embargo -leído desde la búsqueda de antecedentes y precursores- esa elección aunque objetable era aun menos problemática que la del "espacio". Sin pruritos considera "argentinos"

... el Uruguay, el Paraguay, el sur de Bolivia. La historia ha dejado en la literatura de los siglos XVI, XVII, XVIII y XIX, muchos indicios de que todos estos pueblos -la Argentina y sus limítrofes- constituye una sola y futura nación. De ello ha nacido mi panarginismo. ${ }^{17}$

Para el escritor tucumano-santiagueño "pertenecen, pues a la literatura argentina, todas las obras literarias que han nacido de ese núcleo de fuerzas que constituyen la argentinidad, o que han servido para vigorizar ese núcleo." 18

Para Rojas, la nación argentina se despliega en un continuum he- 
geliano y fatal en el que está dispuesto a incorporar incluso hasta el elemento potencialmente más disruptor de esa nacionalidad que construye conscientemente, es decir, al inmigrante, al "cosmopolita" (en sus términos). Lo último que está dispuesto a admitir (y toda la filosofía de la argentinidad que despliega desde los años diez se dirige a demostrarlo) es la inexistencia de la nación argentina y, por ende, de su literatura:

Si no tenemos obra, después de tanto ensayar el teatro, la novela, el poema, haremos historia de nuestras tentativas. Si las obras que tenemos carecen de originalidad, haremos la historia de nuestras imitaciones y trasplantes. Donde la materia no ofrezca ejemplos de enseñanza, estoy seguro que ha de ofrecernos, en sus mismas deficiencias, sugestiones de educación. ${ }^{19}$

La obstinación de Rojas por probar una y otra vez la existencia de la literatura argentina podría llevar a pensar motivos menos entusiastas. Eran tan anémicos y opinables los testimonios literarios argentinos, y tan "en peligro" la "argentinidad", que Ricardo Rojas debe apelar a sus no pocas habilidades de alquimista para alcanzar el vellocino de oro que restaurara blasones y honores opulentos a una patria que juzgaba tan vulnerable como su literatura. Esa fragilidad lo lleva a forjar la tradición con materiales contundentes y rotundos: el bronce y el inventario. Su "pedagogía de las estatuas" y su Historia de la Literatura Argentina, son -a nuestro juicio- las dos concepciones más monumentales para "contener" lo que él supone un riesgoso camino hacia la "disolución" de la nación. Rojas colecciona, compila, "descubre”, cada palabra en verso, cada línea de la prosa, cada proyecto de sensibilidad, por más invisible que parezca, y por más discutible que apareciera, para engrosar su archivo. Adelantándose a lo que podrían ser las críticas a su obra, apela a una legitimidad que muy pocos podían esgrimir: las instituciones. Sobre todo, la cátedra de Literatura Argentina de la Facultad de Filosofía y Letras, pero tampoco desdeña sus acreditaciones personales que enumera exhaustivamente. ${ }^{20}$ Se adelanta a sus eventuales detractores: aunque no hubiera literatura argentina el inventario era una tarea imprescindible para reconocer, incluso, cómo con tantos datos no se lograba vislumbrar el volumen de una nación tan evidente. 
GAUCHOS Y MÁS GAUCHOS PARA

UNA MODERNIDAD PERIFÉRICA

En 1923 Ricardo Rojas ganó el Premio Nacional de Literatura por su Historia. El mismo año, la revista Nosotros -espacio de divulgación y consagración de las letras argentinas- lanzaba su famosa encuesta sobre la orientación estética de las jóvenes generaciones y sobre quiénes eran las referencias literarias entre los escritores mayores de treinta años. Nosotros, pregunta a aquel universo que se ha instalado como sinónimo de protagonismo: los “jóvenes” escritores (de menos de 30 años). Las respuestas son convencionales, pero ratifican el panteón oficial de la nación: Ricardo Rojas, Leopoldo Lugones, Arturo Capdevila, Baldomero Fernández Moreno, Enrique Banchs. La muestra con todo, dista de ser amplia: excluye a los escritores de "izquierda" que comienzan a organizarse con un perfil propio y aspiran a un público masivo. ${ }^{21}$

La revista Nosotros advertía que su monopolio comenzaba a ser discutido. Intentó la asimilación: publicó el Manifiesto Ultraísta, firmado y pensado por Borges. ${ }^{22}$ Sin embargo, la vanguardia ya está en marcha: intenta demoler a la generación del Centenario y con menos reciedumbre, a los "nosotros" que -a partir de entonces- serán "ellos". ${ }^{23}$ Lo anterior muestra el proceso de redefinición, de ruptura que en los veinte llevaron adelante las vanguardias contra todo el sistema de "consagraciones" (premios nacionales, antologías, lugares institucionales). En Argentina se desdobló en dos orientaciones que dieron lugar a la polémica ideológico-literaria más resonante de las letras nacionales: "Boedo versus Florida", muchas veces polarizada por subsecuentes lecturas pasionales o por la necesidad de anclar en ellas precursores y orígenes. Ambos grupos comparten una vocación beligerante con respecto a las generaciones anteriores, pero se dividen las incumbencias: inmigrantes los de Boedo, criollos viejos los de Florida, volcados a la cultura proletaria y a la universalista pedagogía socialista unos, voluntariamente elitistas los otros. Unos enarbolan un viejo gaucho renovado Martín Fierro, los otros remedan a la izquierda de Barbusse con una Claridad. ${ }^{24}$ Moderadamente vanguardistas, ambos, literariamente funcionales y complementarios. 
Para nuestros fines, queremos ejemplificar esa "nueva sensibilidad" en una figura -excepcional a la vez que representativa- que en los años veinte tuvo al tópico nacional como una vocación casi excluyente, vocación que, como veremos quedará clausurada con la década. El muy cosmopolita Jorge Luis Borges en los años veinte escribía “mi argumento de hoy es la patria: lo que hay en ella de presente, de pasado y de venidero." ${ }^{25}$

Borges, como ningún otro escritor de la década del veinte, reinventó otra versión de la historia de la literatura argentina, ${ }^{26}$ pero de una manera voluntariamente fragmentada, descontinua, liviana en sus formas y densa en sus consideraciones. Explícitamente contracara de la compilación voluminosa de Rojas y, por extensión, del denominado primer nacionalismo argentino:

En cuanto a gritadores como Ricardo Rojas, hechos de espuma y patriotería y de insondable nada, son un vejamen paradójico de nuestra verdadera forma de ser. El público lo siente y sin entremeterse a enjuiciar su obra la deja prudencialmente de lado, anticipando y con razón que tiene mucho más de grandiosa que de legible. Nadie se arriesgará a pensar que en Fernández Moreno hay más valía que en Lugones, pero toda el alma nuestra se acordará mejor de la serenidad de uno que con el arduo gongorismo del otro. ${ }^{27}$

El mismo año que apareció Eurindia de Rojas [1924], hace su ingreso a la palestra literaria Martín Fierro. ${ }^{28}$ La revista con un gesto iconoclasta, pugna por entrar en la tradición argentina y elige el no tan añejo pero ya instalado ícono de la argentinidad: el gaucho Martín Fierro. El poema de José Hernández fue recreado, revalorizado y constituido en la síntesis de lo más genuino de la nación, básicamente por Lugones. "Data de 1913 esa valoración, es decir, del primer curso universitario de Rojas, de las conferencias que pronunció Lugones [...] y de la inquisición que aquel año abrieron Roberto Giusti y Alfredo Bianchi en la revista Nosotros. ${ }^{29}$ El gaucho, que había sido considerado la quintaesencia de la barbarie sarmientina, pasaba a ser el arquetipo de la nacionalidad frente a la "nueva" barbarie: los inmigrantes. Si en 
la década del diez el poema de Hernández se coloca en el centro de la polémica, los veinte -sin abandonarlo- producen Don Segundo Sombra, otro gaucho, otro significado; el gaucho que queda definitivamente descartado es Juan Moreira. ${ }^{30}$

Desde una marginalidad que nunca se confundió con modestia, el joven Borges asestó sus dardos contra el indiscutido zar de las letras: Leopoldo Lugones, quien tenía el poder de "ungir" o "excomulgar" a los escritores noveles de la "República de las Letras" desde el decisivo diario La Nación. La ácida crítica de Borges al Romancero de Lugones se inscribe en el gesto corrosivo del vanguardismo respecto de la tradición, pero no para desdeñarla sino para incorporarse a ella. Borges cae inmisericorde contra las rimas de Lugones, lo pone en ridículo. Habla de alguna cuarteta "indecidora, pavota y frívola": "Don Leopoldo se ha pasado los libros entregado a ejercicios de ventriloquia y puede afirmarse que ninguna tarea intelectual le es extraña, salvo la de inventar (no hay una sola idea que sea de él: no hay un solo paisaje en el universo que por derecho de conquista sea suyo)."31

Si en los años veinte, como Borges admitíría después, se escribía "como o contra Lugones", esa centralidad literaria no alcanza para explicar la perentoriedad que tiene Martín Fierro o Proa y -sobre todo Borges- en preguntarse sobre el "ser nacional", tomando como fuente de polémicas los íconos emblemáticos del nacionalismo del Centenario: los gauchos, la ruralidad, el criollismo, problemas bien comprensibles para aquellos nostálgicos de un mundo tradicional y que ven en los inmigrantes, en el cosmopolitismo, en el sufragio universal, en el conflicto social, en síntesis, en la modernidad, señales de peligro y erosión del orden. Para las vanguardias, en cambio, lo nuevo, lo joven, lo moderno, es por definición, lo "bueno". La tecnología (más bien "técnica", en el lenguaje de la época), la velocidad, el cambio, en fin, todo aquello "sólido que se desvanece en el aire", forman parte de su escenario y su sentido. ¿Por qué volver a la pampa y al gaucho?

Sin pretender dar respuestas acabadas consideramos que es la relación entre modernidad y nación una clave explicativa. Ricardo Rojas, Leopoldo Lugones, Manuel Gálvez, prototipos del Centenario, son hombres del interior del país y además, se sienten y han sido hacedo- 
res de la Argentina Moderna, de su sistema educativo, de la construcción de sus símbolos. Con un gesto modernista-novecentista se reconocen como el contrapeso imprescindible de una modernidad disolvente y muy díscola respecto de una "buena sociedad" que conciben tradicionalmente. A esa "bella durmiente" apelan para "forjar" emblemas de una nacionalidad que arraigan en el pasado. Son además "escritores", "letrados" que han ejercido sus producciones en un campo intelectual tan indefinido como lo eran aún la sociedad y el Estado en pleno proceso constitutivo.

Jorge Luis Borges y Ricardo Güiraldes pretenden otra colocación en la "República de las Letras". También son hombres del "interior", ya no de la geografía, sino del interior de la historia argentina. Ambos provienen de familias antiguas y -lejos de recusar ese origen- lo esgrimen como forma de legitimidad. Lo nacional, tópico privilegiado de las letras en toda América Latina, en Argentina era un espacio ya monopolizado por una versión muy cerrada y poco generosa para otras interpretaciones. De allí que las nuevas generaciones literarias (mucho más literarias, además) no encuentren otros intersticios para representar la nación y deban emprender la impugnación de las versiones anteriores (muy recientes, por otra parte, pero ya cristalizadas como tradiciones) para poder "entrar" en el campo de la escritura nacional.

Pensamos que esos son algunos de los contextos que contribuyen a explicar la tenacidad con que una parte de la vanguardia argentina decide volver sobre los consagrados tópicos del Centenario y "expropiar" la nación a los nacionalistas, para poder problematizarla con un sentido más cosmopolita, más universalista y "conversador con el mundo", pero desde el interior de la historia argentina. Una historia a la que Borges no dejará de incomodar con sus paradojas revisionistas (admirar a Rosas y apenarse de San Martín). Una y otra vez antepone los blasones imprescindibles para lanzarse, con la irreverencia de quien está seguro de zanjar un problema de familia, a denostar con adjetivos corrosivos a los nacionalistas. Si su abuelo en 1872 había librado la última batalla importante contra los indios ("haciendo en el siglo XIX la obra del siglo XVI”) el mandato de heroísmo que le adjudicaba la saga familiar era invertir las recientemente antiguas tradiciones literarias ar- 
gentinas. A los socialistas de la revista Claridad, por caso, esa tradición les es ajena y en algún sentido irrelevante, de allí que no tengan las urgencias ni la obligación de abordar el problema nacional en esos términos y sean otras sus preocupaciones: el latinoamericanismo, la literatura "social", la pedagogía proletaria.

“¿Qué hemos hecho los argentinos?”, se pregunta Borges. Como Rojas $^{32}$, también ajusta sus cuentas con el ubicuo Sarmiento: "nos europeizó con su fe de hombre recién venido a la cultura y que espera milagros de ella." A partir de allí hilvana otra tradición en las letras argentinas: Lucio V. Mansilla, Estanislao Del Campo, Eduardo Wilde, pero más aún, Evaristo Carriego, Macedonio Fernández y Ricardo Güiraldes. Descarta aquellos consagrados por una legitimidad que intenta corroer: "Otros nombres dice la fama, pero yo no le creo. Groussac, Lugones, Ingenieros, Enrique Banchs son gente de una época no de una estirpe." ${ }^{33}$

La relectura de la tradición argentina es congruente con su intención de intervenir en el territorio nacionalista, pero esta vez desde el campo exclusivamente literario. Borges separa la literatura del resto de los discursos ${ }^{34}$ e invierte las jerarquías y las modalidades del panteón nacional consagrado por los nacionalistas. Impugna formas y contenidos: la monumentalidad de la Historia de Rojas, su esencialismo, las pautas de selección. Plantea, entonces, la nación y la escritura nacional desde otros prismas:

Muestran las naciones dos índoles: una la obligatoria, de convención, hecha de acuerdo con los requerimientos del siglo y las más veces con el prejuicio de algún definidor famoso; otra la verdadera, entrañable, que la pausada historia va declarando y que se trasluce también por el lenguaje y las costumbres. Entre ambas índoles, la apariencial y la esencial, suele advertirse una contrariedad notoria. ${ }^{35}$

Aquí el tópico por excelencia se dirime en torno al genérico criollismo. Precisamente los significados de Martín Fierro, el gaucho real y el literario, es la clave de bóveda de la discusión sobre la argentinidad. Dice Borges: 
No quiero ni progresismo ni criollismo en la acepción corriente de esas palabras. El primero es un someternos a ser casi norteamericanos o casi europeos, un tesonero ser casi otros; el segundo, que antes fue palabra de acción [...] hoy es palabra de nostalgia [...]. No cabe gran fervor en ninguno de ellos y lo siento por el criollismo. Es verdá que de ensancharse el significado de esa voz [...] sería tal vez la más ajustada a mi empresa. Criollismo, pues, pero un criollismo que sea conversador del mundo y del yo, de Dios y de la muerte. A ver si alguien me ayuda a buscarlo. ${ }^{36}$

En 1926 se publicaron El tamaño de mi esperanza, de Borges y Don Segundo Sombra, de Ricardo Güiraldes, compañeros de la vanguardia que se agrupa en torno a la revista Proa. Ambos buscan una "criolledá” de alcance e intención universalista. Si Borges ya tenía un nombre asentado en el campo literario, los libros de Guiraldes (sobre todo El Cencerro de Cristal y los Cuentos de Muerte y de Sangre) habían sido ignorados por la crítica y el público. Don Segundo Sombra, en cambio, se convirtió en un éxito de crítica y de ventas que no tenía antecedentes. ${ }^{37}$ Sin entrar en la trama de la novela, Don Segundo es la historia de un gaucho viejo, sabio y hábil y su relación con un joven resero, en una pampa cuadriculada por el alambrado y ya domesticada por los patrones. "Si el Facundo presenta al gaucho como victimario -la tesis- y el Martín Fierro como la víctima -la antítesis-, Don Segundo Sombra, escrito al filo de la desaparición del gaucho, lo presenta claramente y auténticamente como maestro." ${ }^{38}$ Frente a la agonía del gaucho real, ese gaucho literario cerró un ciclo de las representaciones de la argentinidad. Esa centralidad de Don Segundo no fue tan espontánea. Lugones leyó los dos libros publicados por Proa y dictaminó. En menos de un mes (12 de septiembre de 1926) apareció la crítica en La Nación: Don Segundo Sombra era "patria pura”. Lugones, que "redescubrió" Martín Fierro en aquellas conferencias del teatro Coliseo de 1913, publicadas en el dieciséis con el nombre de El Payador, creaba su heredero.

Era demasiado laudatoria su crítica y de una generosidad inusual ya que debía sortear el incómodo obstáculo de que Güiraldes, fuera tan "vanguardista" como aquellos que no cesaban de hacer de su persona el centro de las calamidades literarias y políticas del país. Pero sorteó 
ese obstáculo deslizando ese gaucho de la vanguardia hacia el campo de los "héroes literarios" argentinos. Paradójicamente, Borges precisamente en El tamaño de mi esperanza, invertía el panteón literario nacional y señalaba a los -hasta entonces- marginales, entre ellos, a Güiraldes. Pero ignorado por la crítica (Lugones nunca escribió una sola línea acerca de Borges) ese libro fue un fracaso rotundo. Lugones le expropió Don Segundo a Güiraldes (lo sacó de la literatura y lo sumó al "alma nacional”), al tiempo que le expropió a Borges "su" Güiraldes. En 1926 el Premio Nacional de Literatura fue para Ricardo Güiraldes.

Borges, en los años veinte escribió cuatro libros de ensayos: El tamaño de mi esperanza, Inquisiciones, El idioma de los argentinos y Evaristo Carriego. Renegó de los tres (sobre todo del primero y el último), incluso tanto El tamaño... como El idioma de los argentinos fueron purgados por él de sus Obras Completas y reeditados sólo después de su muerte. Borges se autoexilió de su estancia nacional de los años veinte. Hacia finales de los años veinte, advierte la necesidad de "disolver" al criollo para "predecir" la argentinidad:

Hablé de la memoria argentina y siento que una suerte de pudor defiende ese tema y que abundar en él es traición, porque en esta casa de América, amigos míos, los hombres de las naciones del mundo se han conjurado para desaparecer en el hombre nuevo, que no es ninguno de nosotros aún y que predecimos argentino [...]. El criollo es de los conjurados. El criollo que formó la entera nación, ha preferido ser uno de muchos, ahora. Para que honras mayores sean de esta tierra, tiene que olvidar honras. Su recuerdo es casi un remordimiento, un reproche de cosas abandonadas sin la intercesión del adiós. Es recuerdo que se recata, pues el destino criollo así lo requiere, para la cortesía y perfección de su sacrificio. ${ }^{39}$

Silvia Molloy señala que hay una tradición latinoamericana (quizás hispana, considerando a Unamuno) de escritores que articulan la relación sujeto/nación en términos de identidad personal. "Sarmiento, Vasconcelos, aun Martí, no sólo son ciudadanos ejemplares, son (o se representan como) nación, forman con sus patrias un solo cuerpo indisoluble $[. .$.$] . No es mi intención equiparar a Borges con esos héroes$ 
del panteón civil pero sí indicar ciertas coincidencias [...]. Porque si bien Borges no se piensa a sí mismo como nación (el planteo es demasiado monumental, demasiado coherente para quien viene de la vanguardia), sí se piensa y se construye desde un comienzo como escritor nacional." ${ }^{40}$ Pensamos que en las representaciones literarias de la nación, la fijación de precursores, tradiciones, íconos y genealogías se procesan gran parte de los contenidos simbólicos identitarios que la definen. Creemos que esas imágenes también son un territorio de disputa entre las dos formas de concebir la nación: como esencia y como construcción y que este "tironeo" por la paternidad de los "gauchos" literarios argentinos la ejemplifica de manera acabada. Nos parece significativo, además, porque pensamos que en la década del veinte la "argentinidad", la "patria" o la "nación" y sus contenidos se tramita privilegiadamente en el campo de la cultura.

No hay poco de artificio, invención y orfebrería ideológica en la construcción del canon literario. Como afirma Raymond Williams, "la literatura nacional dejó muy pronto de ser historia para convertirse en tradición. Era una selección que culminó, definida de un modo circular, en los "valores literarios" que estaban afirmando la "crítica". Haber sido inglés y haber escrito no significaba de ningún modo pertenecer a la "tradición literaria inglesa" [...]. La selectividad y autodefinición, que constituían los procesos evidentes de la "crítica" de este tipo, eran proyectados no obstante como "literatura", como "valores literarios" y finalmente incluso como "el carácter inglés esencial". ${ }^{41}$ En el caso de las literaturas latinoamericanas, a estos rasgos inherentes a la formación de la tradición se agregaban otras dificultades: la autoconciencia de la "juventud" de estos países y de estas culturas, el obvio problema de la "imitación" o de las "influencias" del exterior y, sobre todo, la comunidad idiomática de América, lo que hacía más complejo el recorte de las personalidades nacionales entre los países de la región y, también, respecto de España y los críticos españoles. A nuestro juicio esto subrayó el carácter de artefacto cultural y, también el frecuente recurso de apelar a cuestiones extra-literarias para cercar sus objetos. Destacamos este carácter "circular" de las argumentaciones: hay "nación" porque existe una tradición literaria "propia" y los criterios de selección de este 
corpus responden a aquella producción que "refleja" el espíritu nacional. Finalmente, la explicación remite a cierta sustancia ontológica, el "espíritu nacional" y, por tanto, ahistórica.

La nación como concepto, parece conjugar lo particular y lo universal. Y las historias de las literaturas nacionales, otro tanto. Así, por ejemplo, la tensión entre lo universal y lo particular (tratándose de productos culturales cuya legitimidad estética también está pautada por una tradición genéricamente europea) atraviesa las preocupaciones de los críticos. Sin renegar de esas referencias (la crítica española o francesa, por caso), algunos tienden a subrayar lo particular, lo esencial, lo original de la producción nacional, aun en desmedro de su valor estético. Otros intentan ser más respetuosos con lo que hoy llamaríamos las "reglas del campo" para, sin embargo, también reclamar originalidad pero, esta vez, en el concierto de la literatura universal.

En los años veinte, entre Guiraldes, Borges, Rojas y Lugones se dirime la "cuadratura del círculo nacional". El año 1930 clausura muchas de esas búsquedas, concentra y radicaliza otras, a veces paradojales. Ricardo Guiraldes murió prematuramente, al año de la aparición de Don Segundo y quedó fijado por él. Borges abandonó sus gauchos y recurrió con menos frecuencia al ensayo. Leopoldo Lugones, que venía anunciando "la hora de la espada" desde 1924, apoya y escribe la proclama del golpe de Estado del General Uriburu en 1930. Ricardo Rojas, frente al golpe, se afilia al partido radical y es acusado de inspirar una insurreción contra el gobierno de facto. Es confinado a la lejana Usuhaia donde escribe un puntilloso estudio sobre el más austral de los paisajes que llamó Archipiélagos. En 1938 Lugones se suicidaba en una isla del Delta. El obituario que escribe Borges para la revista Nosotros marca el comienzo de una reconciliación que sellará años más tarde con su famoso prólogo sobre El Payador. El hijo de Lugones, comisario de la Sección Especial de la Policía Federal, triste inventor de la picana eléctrica para torturar a los acusados de comunismo, le prologó casi todos sus libros. Borges evitó mencionar el asunto. Era demasiado literario. Incluso para él. 
FUNES, P. Reading verses with the eyes of History. Literature and Nation in Ricardo Rojas and Jorge Luis Borges. História. São Paulo, v. 22, n.2, pp. 99-120, 2003.

ABSTRACT: The article analyzes the representations of "Argentinity"/AArgentine Identity" from the construction of the literary canon in the twenties. In this opportunity we chose to confront the essayistcs by Ricardo Rojas and Jorge Luis Borges. To our opinion, the bases on the existence or the voluntary construction of a "history of the National Literature" discovers its selection mechanisms, hermeneutics and supports, the conflict to define the meanings of the national identity. Particularist or universalist, traditionalist or vanguardist, the matter goes beyond the field of literature and it establishes the basis of images, symbols and stereotypes which are poured onto the representations of society and politics.

KEYWOR D : nationalism, vanguard, histories of Literature.

\section{NOTAS}

${ }^{1}$ Facultad de Ciencias Sociales de la Universidad de Buenos Aires. Investigadora del Instituto de Investigaciones Gino Germani de la Universidad de Buenos Aires. Marcelo T. de Alvear, 2230 - 1122 - Buenos Aires - Argentina.

${ }^{2}$ La obra de Rojas salió editada por primera vez con el nombre de Literatura argentina. Ensayo filosófico sobre la evolución de la cultura en el Plata; La Facultad, Buenos Aires, 1917-1922. En la tercera edición llega a su título definitivo: Historia de la Literatura argentina. Ensayo Filosófico sobre la evolución de la cultura en el Plata; Losada; Buenos Aires; 1948. La primera edición salió publicada en cuatro tomos: "Los gauchescos" (1917); "Los coloniales" (1918); "Los proscriptos" (1919) y "Los modernos" (1922). En este trabajo se cita la cuarta edición, en 9 tomos, Editorial Guillermo Kraft, Buenos Aires, 1957.

${ }^{3}$ ZUM FELDE, A., Crítica de la litaratura uruguaya, Montevideo, Maximino García Editores, 1921, pp. 6-7. Hemos tratado comparativamente las historias de la literatura en Uruguay y Argentina en un trabajo anterior. Funes, Patricia, "Letras nacionales nacidas en vientre de leona. Literatura y nación en Argentina y Uruguay, 1910-1920", en: Estudios Sociales. Revista Universitaria Semestral, n. 17, segundo semestre, 1999, pp. 9-34. 
${ }^{4}$ Luis Alberto Sánchez publicó, en 1928, el primer tomo de un largo estudio sobre la literatura peruana. En él expone el plan de la obra y los fundamentos teóricos de la misma. SANCHEZ, L. A. Literatura Peruana. Lima: Universidad de San Marcos, 1928. Aquí se cita la síntesis de ese estudio, expuesta en una serie de Conferencias realizadas por Sánchez en La Facultad de Filosofía y Letras de la Universidad de Buenos Aires [La Literatura del Perú. Buenos Aires: Imprenta de la Universidad-Instituto de Cultura Latino-Americana, 1939, p. 15].

${ }^{5}$ Idem, p. 13.

${ }^{6}$ ROJAS, R. Historia de la Literatura Argentina. Ensayo filosófico sobre la evolución de la cultura en el Plata, Tomo I, Prólogo, p. 64.

${ }^{7}$ Rojas, R. Op. cit., p. 65.

${ }^{8}$ Idem, p. 24.

${ }^{9}$ Idem, p. 65. El énfasis es nuestro.

${ }^{10}$ MARIÁTEGUI, J. C. Proceso de la literatura, en: Siete ensayos de interpretación de la realidad peruana. Cidad del México: Era, 1979, p. 209.[El original: 1928].

${ }^{11}$ Idem, p. 207.

${ }^{12}$ BELAÚNDE, V. A. La evolución de nuestra cultura. En: Meditaciones Peruanas. Lima: Compañía de impresiones y publicidad editores, 1932, p. 134.

${ }^{13}$ Idem, pp. 135-136.

${ }_{14}$ "Incluído el período colonial, nuestra historia literaria podría dividirse, para su exposición didáctica, en los siguientes períodos cronológicos, más o menos referidos a la historia política [...]. $1^{\circ}$ Los orígenes: desde las primeras ciudades [...] hasta la fundación de la enseñanza universitaria; $2^{\circ}$ La iniciación: desde la fundación de la Universidad de Córdoba [...] hasta la expulsión de los jesuitas (1767); 3º La revolución: desde la expulsión de los jesuitas y las reformas virreinales (1776) hasta el ocaso de la generación de Mayo (1820); 4ํㅡㄴ La proscripción: desde los caudillos y Rosas (1820) hasta Caseros (1852); 5ㅜㅡ La organización: desde la consituyente (1853) hasta el congreso de Belgrano (1880); $6^{\circ}$ La actualidad: desde la federalización de Buenos Aires hasta el triunfo de la burguesía cosmopolita. Rojas, R.; Historia...; Introducción; pp. 37-38.

${ }^{15}$ ALTAMIRANO, C. La fundación de la literatura Argentina. En: ALTAMIRANO, C. y SARLO, B. Ensayos argentinos. De Sarmiento a la vanguardia. Buenos Aires: Centro Editor de América Latina, Buenos Aires, 1983, p.115.

${ }^{16}$ ZUM FELDE, A. Noticia acerca de la poesía uruguaya contemporánea. En: Nosotros, Buenos Aires, año XIX, n. 192, Marzo, 1925, p.6.

${ }^{17}$ ROJAS, R. Op. cit., p. 34. 
${ }^{18}$ Idem

${ }^{19}$ Idem, pp. 64-65.

20 "No necesito advertir que he puesto al servicio de esta obra todas mis experiencias docentes y literarias, y me será permitido recordar, sin vanidad alguna, que soy catedrático de literatura argentina en la Universidad de Buenos Aires (Facultad de filosofía y letras); de literatura castellana en la Universidad de La Plata (Facultad de ciencias de la Educación); profesor o ex profesor de gramática, estética literaria, psicología e historia de la civilización en diversos institutos de enseñanza normal y especial; miembro de la Academia de la lengua, de la Junta de historia y numismática, de la Sociedad científica, de otras instituciones de cultura; consejero académico en la Universidad de La Plata; encargado de conferencias en la Universidad de Tucumán, el Ateneo de Madrid, el Museo de bellas artes de Buenos Aires, la Sociedad wagneriana, etc; ex comisionado del ministerio de Instrucción Pública para estudiar en Europa los métodos de la historia [...]; sin contar mis libros relacionados todos, directa o indirectamente con los temas de esta obra." Idem, p. 65. Recordemos que Rojas que creó la primera cátedra de Literatura Argentina del país (1912), el primer Instituto de Literatura Argentina (1922) y el Instituto de Filología, no contaba con ningún grado universitario.

${ }^{21}$ La encuesta comienza a publicarse en el número 168 del mes de mayo de 1923. Contestan treinta y siete escritores.

${ }^{22}$ Nosotros. Buenos Aires, año 15, n. 151, diciembre, 1921, pp. 466-467.

${ }^{23}$ En la década se multiplicaron las revistas literarias y culturales. Entre ellas: Proa (agosto 1924-enero 1926), dirigida por Jorge Luis Borges, Revista de América (diciembre 1924-julio 1926) dirigida por Carlos Erro. Ligadas al movimiento universitario reformista: Valoraciones (septiembre 1923-Mayo 1928), dirigida por Alejandro Korn, y Sagitario (mayo-junio 1925-noviembre 1928) dirigida por Carlos Amaya.

${ }^{24}$ Claridad fue parte del proyecto pedagógico socialista encabezado por Antonio Zamora. En 1922 comenzó la publicación de cuadernillos semanales con "obras selectas" de la literatura universal, en una colección que llamó Los Pensadores.Publicación semanal de Obras Selectas. Los libros eran muy baratos y en octubre de 1927 la editorial se jactaba de publicar un libro por día, lo que suponía no sólo un público consumidor sino también una moderna capacidad editorial. El primer número de Claridad, Tribuna del pensamiento izquierdista, apareció en julio de 1926 y salió regularmente hasta diciembre de 1941. En su primer editorial manifestaba sus objetivos: "Claridad aspira a ser una revista en cuyas páginas se reflejen las inquietudes del pensamiento izquierdista en todas las manifestaciones. Deseamos estar más cerca de las luchas sociales que de las manifestaciones puramente literarias. Creemos de más utilidad para la humanidad del porvenir las luchas sociales 
que las grescas literarias, sin dejar de reconocer que una contienda literaria puede también volver a surgir una nueva escuela que interpele las manifestaciones humanas en forma que estén más de acuerdo con la realidad de la época que vivimos". “Apuntes y Comentarios”. Claridad. Buenos Aires, Año I, n. 1, julio, 1926, p. 1.

${ }^{25}$ BORGES, J. L. El tamaño de mi esperanza, Buenos Aires: Seix Barral, 1993. [Primera edición: 1926], p. 14.

${ }^{26}$ MONTALDO, G. Borges: una vanguardia criolla. En: MONTALDO, G. y otros. Yrigoyen entre Borges y Arlt (1916-1930), Buenos Aires: Contrapunto, 1989, p. 213.

${ }^{27}$ BORGES, J. L. Queja del criollo. En: Inquisiciones. Buenos Aires: Alianza, 1998, pp. 147-150. [La primera edición es de 1925].

${ }^{28}$ Martín Fierro salió desde febrero de 1924 hasta noviembre de 1927.

${ }^{29}$ MONNER SANZ, J. La historia de la literatura argentina de Ricardo Rojas. En: Revista Iberoamericana. Organo del Instituto Internacional de Literatura Iberoamericana, v. XXIII, n.. 46, julio-diciembre, 1958, p. 277.

${ }^{30}$ Moreira, es -para Manuel Gálvez- la representación de las tendencias agresivas, la afición a la guapeza; el "moreirismo" expresa "nuestro espíritu faccioso, nuestro culto al coraje y nuestra manía revolucionaria" [GÁLVEZ, Manuel, Diario de Gabriel Quiroga, Buenos Aires, Antonio Moen Editores, 1910, p.225]. Esa valoración no parece coincidir con la trascendencia y difusión del Juan Moreira de Ricardo Gutiérrez entre las clases populares, para las que Martín Fierro más bien venía a complementar al Juan Moreira de Gutierrez. "Juan Moreira sumaba [...] muchos elementos a su favor para marcar el tomo y las tendencias de una literatura de consumo popular. Contaba una historia excitante, sólida, emocional, en la que sucesivamente podían canalizarse la pura voluntad de entretenimiento, la sublimación de todas las humillaciones sufridas y el designio de secretas rebeldías." PRIETO, A. El discurso criollista en la formación de la Argentina Moderna. Buenos Aires: Sudamericana, 1988, p. 99.

${ }^{31}$ BORGES, J. L. Leopoldo Lugones. Romancero. En: El tamaño..., pp. 95-96.

${ }^{32}$ Recorriendo la ensayística de Borges de la década de 1920 pueden advertirse varias preguntas comunes con los nacionalistas del Centenario. En la mayoría de los casos invierte sus respuestas, pero no siempre. Vaya un ejemplo. Ya se sabe que Rojas veía con preocupación la "colonización” "gringa” de la ciudad. Rojas eligió un ícono: la estatua de Garibaldi de Plaza Italia. Si los italianos habían levantado una estatua de Garibaldi el Estado debería convocar a algún escultor para erigir al lado alguna de un gaucho o prócer vernáculo. Curiosamente, en Borges también se encuentra esa preocupación por la "invasión” del espacio público por parte de las culturas inmigrantes: "El chorreado caballo verdinoso y su Garibaldi no deprimían los Portones antiguos (La dolencia es general: no queda plaza que no esté padeciendo 
su guarango de bronce.)." ["Palermo de Buenos Aires". En: Evaristo Carriego. Buenos Aires: Alianza, 1994, p. 21 [El original es de 1930].

${ }^{33}$ BORGES, J. L, Op. cit, p. 11.

${ }^{34}$ MONTALDO, G. Op. cit., p. 225.

${ }^{35}$ BORGES, J. L., Queja del criollo. En: Inquisiciones, pp. 147-150.

${ }^{36}$ BORGES, J. L., El tamaño de mi esperanza, p. 14.

${ }^{37}$ En dos semanas se agotó la primera edición de 2000 ejemplares.

${ }^{38}$ BORDELOIS, I. Un triángulo crucial. Borges, Güiraldes y Lugones. Buenos Aires: EUDEBA, 1999, p. 98.

${ }^{39}$ BORGES, J. L. "Página relativa a Figari”, leída con motivo de la exposición de cuadros de Pedro Figari realizada en el Convivio de los Cursos de Cultura Católica, aparecida en Criterio, año I, n. 30, 27 de septiembre de 1928.

${ }^{40}$ MOLLOY, S. Argentinos en el espejo: una reflexión sobre Borges. En: ALTAMIRANO, C. [Ed.], La Argentina en el siglo XX. Buenos Aires: Ariel-UNQ, 1999, pp. 87-88.

${ }^{41}$ WILLIAMS, R. Marxismo y literatura. Barcelona: 1977, pp. 66-67.

Artigo recebido em 05/2003, aprovado em 07/2003. 